\title{
Linkage between the dominant modes in Pacific subsurface ocean temperature and the two type ENSO events
}

\author{
XU Kang ${ }^{1,2}$, ZHU CongWen ${ }^{2 *} \&$ HE JinHai ${ }^{1}$ \\ ${ }^{1}$ Key Laboratory of Meteorological Disaster of Ministry of Education, Nanjing University of Information Science and Technology, Nanjing \\ 210044, China; \\ ${ }^{2}$ Institute of Climate Systems, Chinese Academy of Meteorological Sciences, Beijing 100081, China
}

Received February 20, 2012; accepted March 16, 2012; published online May 15, 2012

\begin{abstract}
We investigate the variations of subsurface ocean temperature (SOT) based on the monthly-Simple Ocean Data Assimilation (SODA) during 1958-2007, and discuss the linkage between the variations of SOT and the eastern and central Pacific ENSO (EP and CP-ENSO) events. The wavelet analyses suggest that the variation of the EP and CP-ENSO events shows the 2-7 and the 10-15 years oscillation in the tropical sea surface temperature (SST), and coupled with a zonal dipole mode and a tripole mode in the SOT anomalous field reveled by the singular value decomposition (SVD) analysis. During the mature phase of CP-ENSO, the positive center of SOT at the subsurface layer locates in the west of dateline, which results in the increase of SOT in the Niño4 region and causes the CP-ENSO event. Statistical analysis implies that, the eastern and central Pacific subsurface indices which are defined by the expansion coefficients of the first and third SVD mode for SOT have shown the capabilities in disguising the EP and CP-ENSO events, respectively. In addition, corresponding to the increase of the SOT amplitude on the 10-15 years time scale, we found that the frequency and intensity of CP-El Niño events has exhibited an upward trend after the 1980s, which suggests that the CP-ENSO event has shown an enhanced impact on the global climate in the past decades.
\end{abstract}

dominant modes, subsurface ocean temperature, EP- and CP-ENSO, coupled mode

Citation: Xu K, Zhu C W, He J H. Linkage between the dominant modes in Pacific subsurface ocean temperature and the two type ENSO events. Chin Sci Bull, 2012, 57: 3491-3496, doi: 10.1007/s11434-012-5173-4

The El Niño-Southern Oscillation (ENSO) and its impacts on the global climate has been widely explored over the past decades. A number of studies suggest that the ENSO mainly exhibits a 2-7 years variation, which is characterized by the warming (El Niño) and cooling (La Niña) sea surface temperature anomalies (SSTA) in the eastern and central equatorial Pacific [1-5]. Recently, a new type of ENSO, so called "Dateline El Niño", "El Niño Modoki" (EMI), and "Warm pool El Niño" has been subsequently explored and defined by Larkin and Harrison [6], Ashok et al. [7] and Kug et al. [8]. In order to distinguish the traditional Eastern-Pacific (EP) type of ENSO event, it is also called Central-Pacific (CP) ENSO by Kao and Yu [9], and the EP and $\mathrm{CP}$ indices are closely associated with the first and second

*Corresponding author (email: tomzhu@ cams.cma.gov.cn)
EOF modes of the equatorial Pacific SST anomalies, respectively. The previous studies suggest that the two type ENSO events are quite different in the spatial patterns, periodicities, and teleconnections in the SSTA field; therefore, two new Niño indices (warm-pool index and cold-tongue index) by a simple nonlinear transformation based on Niño3 and Niño4 SSTA indices are suggested to indicate the two types of ENSO events respectively by Ren and Jin [10], and they found that the main patterns, phase propagations and regime changes of the two types of ENSO events can be conveniently delineated using these two indices. However, the previous works mainly discussed the interannual variability of the two types of ENSO events. Recently, it is found that there exists a prominent interdecadal (10-15 years) signal in the time series of ENSO intensity and El Niño Modoki indices [7,8,11,12], which implies that the two 
types of ENSO events are possibly controlled by the different physical processes [13].

$\mathrm{Yu}$ et al. [14] and $\mathrm{Yu}$ and Kim [15] found that the EPENSO is possibly produced by the delayed oscillator or the recharged oscillator after they have examined the structure of subsurface ocean temperature (SOT), but the possible linkage between the CP-ENSO and the SOT variations is still unclear. In this regard, the aim of this study is to identify the possible linkage between the two types ENSO events and the variations in the SOT anomalies, particularly on the interdecadal time scale.

\section{Data and methods}

The monthly Sea Surface Temperature (SST) utilized in the present study is derived from the Met Office Hadley Center Sea Ice and Sea Surface Temperature dataset (HadISST), girded at $1.0^{\circ} \times 1.0^{\circ}$ resolution [16]. The monthly subsurface ocean temperature (SOT) is taken from a retrospective analysis of the global ocean based on the Simple Ocean Data Assimilation (SODA version 2.0.2-4) package [17,18]; this dataset covers the global oceans with $0.5^{\circ} \times 0.5^{\circ}$ horizontal resolution and 40 standard depth levels in the vertical direction, spanning the period of January 1958 to December 2007 [19]. Evolution suggests that the variation of SOT derived from SODA exhibits a homogeneous change with the SST anomaly in HadISST over the tropical Pacific region after 1950s [20], therefore, we choose the both datasets during 1958-2007 in present study. We applied singular value decomposition (SVD) to reveal the coupled linkage between SST and SOT anomalies in the tropical Pacific. In addition, the wavelet, Butterworth filter analyses and lead/ lag correlations are applied in this study to discuss the possible difference between the EP and the CP-ENSO events.

\section{Coupled modes between the tropical Pacific SST and the SOT fields}

Figure 1 shows the wavelet analysis of the time series of Niño3.4 $\left(5^{\circ} \mathrm{S}-5^{\circ} \mathrm{N}, 170^{\circ}-120^{\circ} \mathrm{W}\right)$, Niño3 $\left(5^{\circ} \mathrm{S}-5^{\circ} \mathrm{N}, 150^{\circ}-\right.$ $\left.90^{\circ} \mathrm{W}\right)$, and Niño4 $\left(5^{\circ} \mathrm{S}-5^{\circ} \mathrm{N}, 160^{\circ} \mathrm{E}-150^{\circ} \mathrm{W}\right) \mathrm{SST}$ anomalous indices during 1958-2007. The wavelet power spectrums suggest that there exist $2-7$ and $10-15$ years oscillations in the time series of Niño3.4, Niño3, and Niño4 SSTA indices, but the global power spectrums suggest that the 27 -year oscillation is significant in these Niño regions, which has been discussed by many studies $[1,21]$. In contrast, the remarkable 10-15 years oscillation is only significant in the Niño4 region where CP-ENSO prevails [11]. If we refer to the 2-7 and 10-15 years band pass filtered SST as interannual and interdecadal components of SST anomalies and calculated their variances during 1958-2007 (figures is not shown), we found that similar to the EP-ENSO events, the
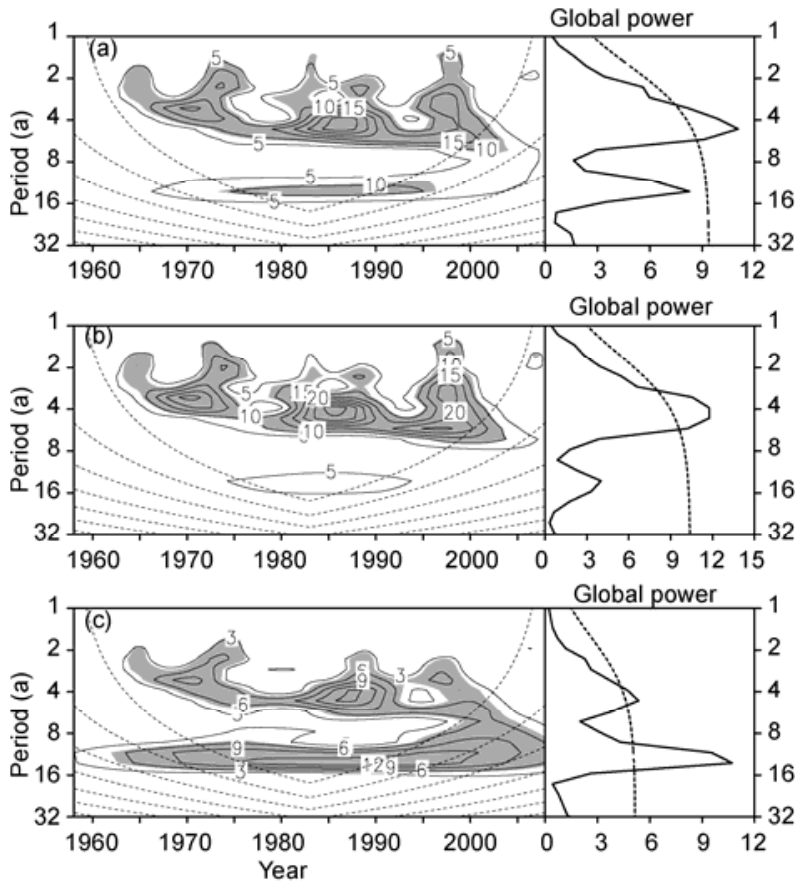

Figure 1 The wavelet analysis and the global power spectrum of monthly Niño indices in (a) Niño3.4, (b) Niño3, and (c) Niño4 regions. The shaded area designates statistically significant at $95 \%$ confidence level against red noise process, and the regions of dashed lines on either end indicate the "cone of influence", where edge effects become importance. In the right panel, the solid line is the global wavelet power spectrum and the dashed line shows its significance level at 0.05 .

interannual variances of SST anomalies mainly appear in the Niño3.4 region $\left(10^{\circ} \mathrm{S}-10^{\circ} \mathrm{N}, 160^{\circ}-80^{\circ} \mathrm{W}\right)$. In contrast, the interdecadal variances cover the Niño3.4 and Niño4 regions, from $10^{\circ} \mathrm{S}$ and $10^{\circ} \mathrm{N}$ between $160^{\circ} \mathrm{E}$ to $120^{\circ} \mathrm{W}$. But, the interdecadal variances are greater than the interannual counterparts in the Niño4 region, which implies that the CP-ENSO mainly exhibits an interdecadal oscillation and prevails over the central Pacific, but the EP-ENSO primarily displays an interannual oscillation and active in the eastern Pacific.

To explore the possible coupled mode between the SST and the SOT anomalies, we apply the SVD method to the left field of SST $\left(30^{\circ} \mathrm{S}-30^{\circ} \mathrm{N}, 120^{\circ} \mathrm{E}-80^{\circ} \mathrm{W}\right)$ and the right field of SOT (upper $350 \mathrm{~m}$ levels, averaged between $5^{\circ} \mathrm{S}$ and $5^{\circ} \mathrm{N}$ in the tropical Pacific) during 1958-2007. Figure 2 shows the first SVD mode and the corresponding time series of the expansion coefficients, where the leading SVD mode accounts for $84.26 \%$ of the total squared covariance and the variance fraction in the SST and SOT anomalous fields is $25.42 \%$ and $32.69 \%$, respectively. Figure 2(a) and (b) suggests that the first coupled SVD mode displays a traditional El Niño pattern in the SST and SOT anomalies. It is found that a traditional dipole of SSTA pattern appears in the tropical Pacific with the warming center locating in the eastern and central equatorial Pacific, corresponding to a typical zonal dipole of SOT anomalies at the subsurface layer over the tropical Pacific. The center of negative 


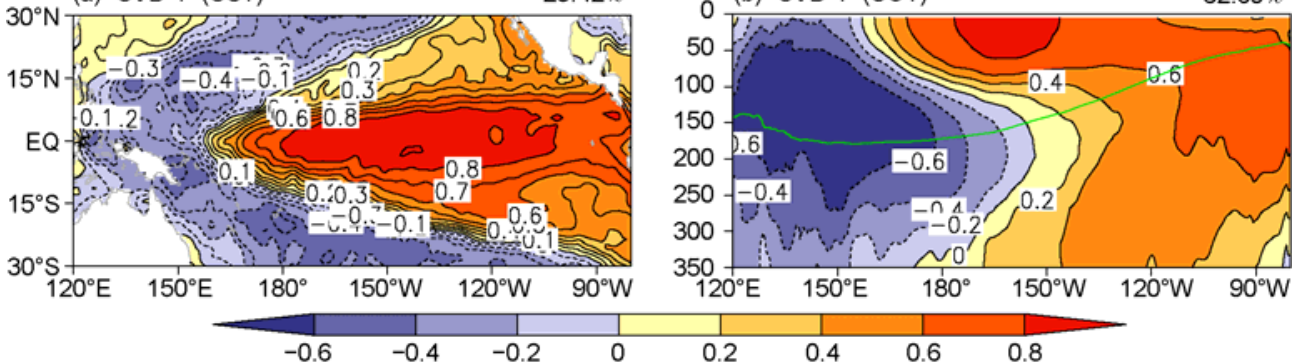

(c) PCs for 1st SVD $R=0.92$

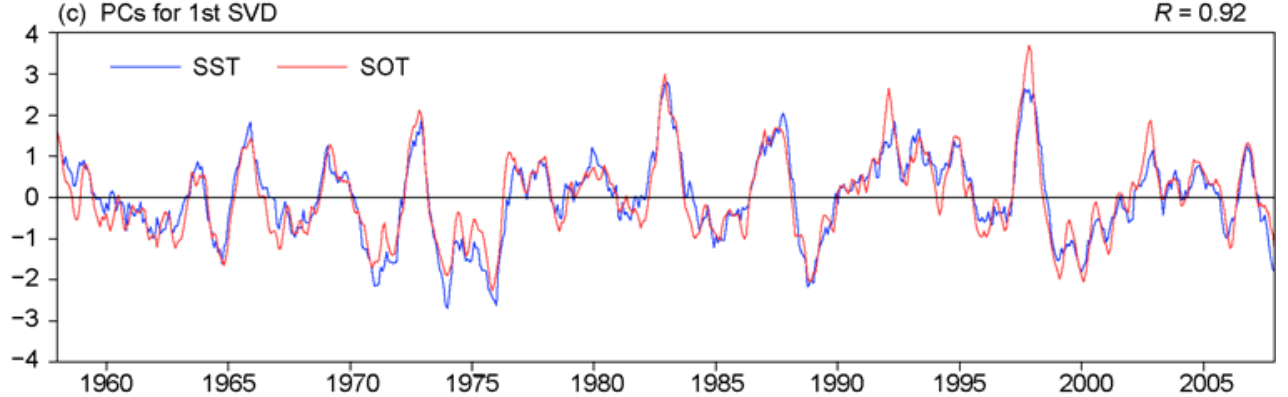

Figure 2 The first SVD mode of the SST (a) and the SOT anomalous fields (b) and their expansion coefficients during 1958-2007 (c). The expansion coefficient for SST and SOT is indicated by the blue solid line and the red solid line, respectively. In (a) and (b), units are arbitrary, and the green bold curve in (b) is the climatological mean of the $20^{\circ} \mathrm{C}$ isotherm. Variance fraction in the SST and SOT is expressed as a percentage printed in each title, the correlation coefficient between the expansion coefficients is printed in the right panel in (c).

$\left(150^{\circ} \mathrm{E}, 150 \mathrm{~m}\right)$ and the positive SOT anomalies $\left(160^{\circ}-\right.$ $100^{\circ} \mathrm{W}, 50 \mathrm{~m}$ ) are obvious along the equatorial Pacific thermocline (Figure 2(b)). The correlation coefficient between the first pair of expansion coefficients is +0.92 and both expansion coefficients exhibit the $2-7$ and $10-15$ years oscillations explored by the wavelet power spectrums. However, the global power spectrum mainly displays a 2-7 years oscillation, which implies that the EP-ENSO is mainly coupled with a zonal dipole at the upper layer of SOT over the tropical Pacific on interannual time scale. The second SVD mode displays a spatial distribution in the SST and SOT anomalies, corresponding to a joint linear trend revealed by the time series of expansion coefficients (figures not shown).

Figure 3 shows the third pair of SVD modes for the SST and SOT anomalies and their expansion coefficients. It is clearly found that the SVD displays a dominant CP-ENSO pattern in the SST anomalies, but it is associated with a tripole structure in the zonal SOT anomalous field. Such result implies that an enhanced (suppressed) SST over the central tropical Pacific (the eastern and western tropical Pacific) is usually associated with the warming (cooling) of SOT anomalies over the upper layer in the central Pacific region. The squared covariance fraction of the third SVD mode is $4.84 \%$, and the variance fractions in the SST and SOT anomalous fields account for $8.16 \%$ and $8.45 \%$, respectively. The correlation coefficient between the expansion coefficients of the third SVD mode is +0.76 , and both expansion coefficients exhibit a remarkable 10-15 years oscillation, as reveled by the wavelet analysis (figure not shown). There- fore, the CP-ENSO event in the SST anomalies is usually coupled with the upper layer warming of SOT over the central Pacific on interdecadal time scale.

However, some of previous works suggest that the EMI-related SOT exhibits a dipole structure over the equatorial Pacific region [7,9]. We noted that the first two EOFs of SST anomalies during 1979-2005 explored by Ashok et al. [7] accounts for $45 \%$ and $12 \%$ of the total variance, respectively, which suggests that the EP-ENSO is still a dominant mode in the SST anomalous field. The EMrelated second EOF of SST anomalies implies that when the SST warming occurs in the central region $\left(\mathrm{C}: 165^{\circ} \mathrm{E}-\right.$ $\left.140^{\circ} \mathrm{W}, 10^{\circ} \mathrm{S}-10^{\circ} \mathrm{N}\right)$, the associated counterparts over the western (W: $125^{\circ}-145^{\circ} \mathrm{E}, 10^{\circ} \mathrm{S}-20^{\circ} \mathrm{N}$ ) and eastern Pacific region $\left(\mathrm{E}: 110^{\circ}-70^{\circ} \mathrm{W}, 15^{\circ} \mathrm{S}-5^{\circ} \mathrm{N}\right)$ should coherently exhibit a cooling feature. In fact, due to the impact of EP-ENSO, the SST anomaly index in the above three regions could not exhibit the significantly coherent variation in the raw SST anomalous field. For instance, the SST indices in the western and eastern region exhibit a negative correlation, the correlation coefficient is -0.1 (figure omitted). Such a result implies that the EMI has highlighted the warming (cooling) of SST over the central Pacific. As a result, the EMI may indicate the interannual variability of CP-ENSO events to some extent, but it could not represent the interannual variation of CP-ENSO modes. In addition to the impact of EPENSO on the EMI-related structure in the SST and the SOT anomalies, the other impacts may come from the long-term trend and residual signals. In present study, however, the EPENSO and the long-term trends of SST and SOT anomalies 
(a) SVD-3 (SST)

$8.16 \%$

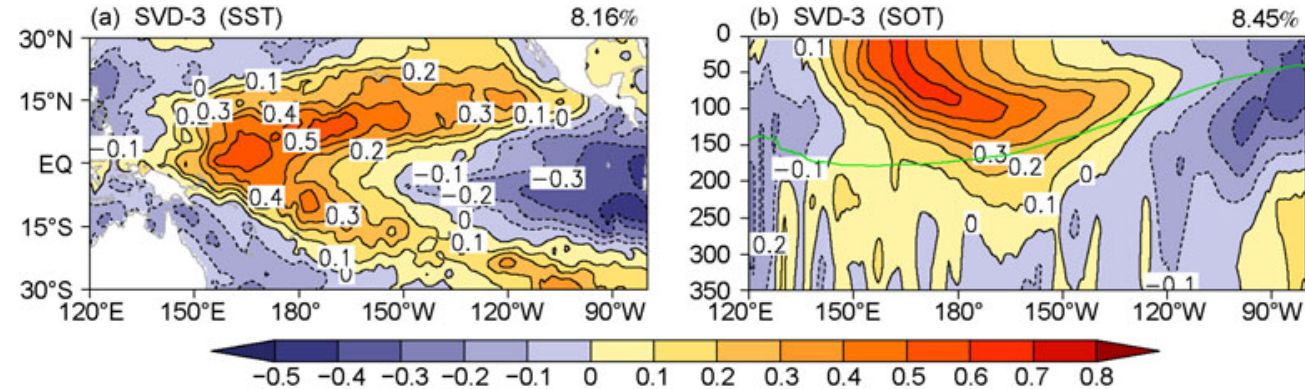

(c) PCs for 3rd SVD

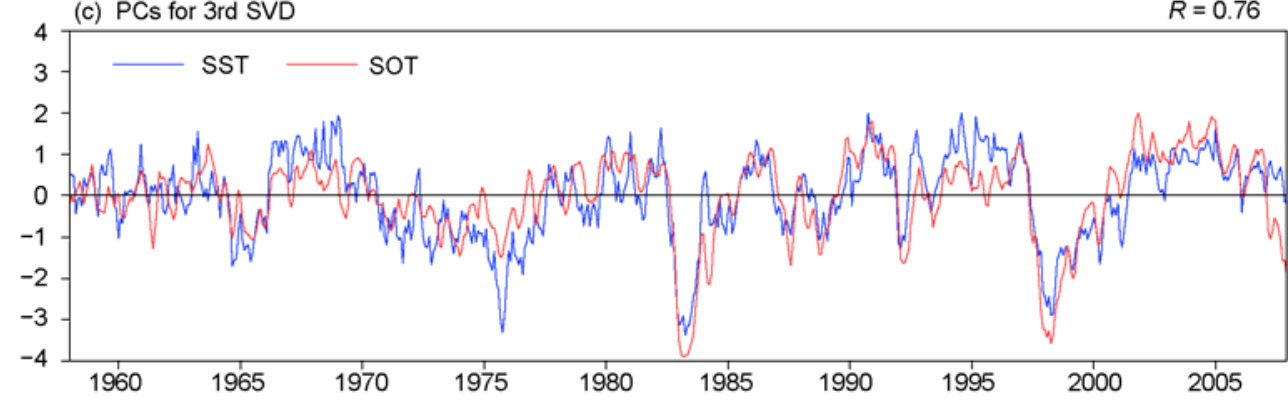

Figure 3 Same as in Figure 2, but for the third SVD mode.

have been removed by the first two SVD modes. As a result, the CP-ENSO pattern indicated by the third SVD between the SST and SOT anomalies exhibits a tripole structure over the tropical Pacific.

\section{Linkage between the variations of SOT and the two type ENSO events}

The Niño3.4 SST anomaly index has been widely used to indicate the ENSO events in the past studies. However, Trenberth and Stepaniak [22] pointed out that the Niño3.4 SST could not distinguish the canonical El Niño and the El Niño occurring in the central Pacific. The EP and CP-ENSO events were defined mainly based on the SST anomalies, however, Kao and $\mathrm{Yu}$ [9] suggests that Niño3.4 index is not good at capturing the EP- and CP-ENSO event. Our results suggest that the variations of EP and CP-ENSO events are usually associated with a zonal dipole and tripole pattern of the SOT anomalies on the interannual and interdecadal time scales, respectively. Such a result implies that the variations of dominant modes of SOT are closely linked to the two types ENSO events. Therefore, we defined the first and third expansion coefficients of the SVD mode for SOT as the eastern Pacific subsurface index (EPSI) and central Pacific subsurface index (CPSI) and discuss their possible linkage to the two types ENSO events. The warm center of SOT may shift during an ENSO cycle, we found that the peak of EPSI and CPSI are clearly corresponding to the mature phases of two types of ENSO events, which is characterized by the lag/lead correlations of EPSI and CPSI with SOT anomalies at different depths in meters averaged over $5^{\circ} \mathrm{S}-5^{\circ} \mathrm{N}$ (figure omitted). In present study, we chose two
EP and CP-ENSO indices, respectively defined by Kao and $\mathrm{Yu}$ [9] (referred to as EPI and CPI) and Ren and Jin [10] (referred to as CTI and WPI). Figure 4 shows the three pairs of normalized time series of two types ENSO indices during 1958-2007. The time series of EPSI exhibits a remarkable interannual variability, the correlation coefficient between the EPI (CTI) and the EPSI is $+0.4(+0.82)$, which suggest a highly correlation between the CTI and EPSI. The wavelet analysis imply that there is a highly statistically significant 2-7-year periodicity in these three EP-ENSO indices (figure is not shown). Therefore, the EPSI displays a better performance in capturing the interannual variability of EP-ENSO event. In the case of CP-ENSO event, we found the CPSI has a significant correlations with CPI and WPI (the correlation coefficients are +0.61 and +0.59 , respectively), which implies the linkage between the CPSI and CP-ENSO events. The time series of CPSI and the WPI both exhibit a remarkable 10-15 years oscillation, but it is weak in the CPI defined by Kao and $\mathrm{Yu}$ [9] (figure not shown). Past studies suggest that the intensity of El Niño and La Niña exhibits asymmetry in the amplitude [9,23,24]; our statistical analysis suggests that in the case of the EP-ENSO events defined by EPSI, the stronger El Niño events exhibits a higher frequency than the strong La Niña events. But, in the case of CP-ENSO events, the strong La Niña events show a higher frequency than the strong El Niño events (Figure 4).

Following the previous definitions, an El Niño or La Niña event in present study, is defined when the ENSO indices exceeding one standard deviation and lasting for at least three months. Based on the definition of Kao and $\mathrm{Yu}$ [9], we found there are 5 and 11, 10 and 9 cases corresponding to the EP-El Niño and La Niña events, CP-El Niño and La Niña events during 1958-2007, respectively. In accordance 

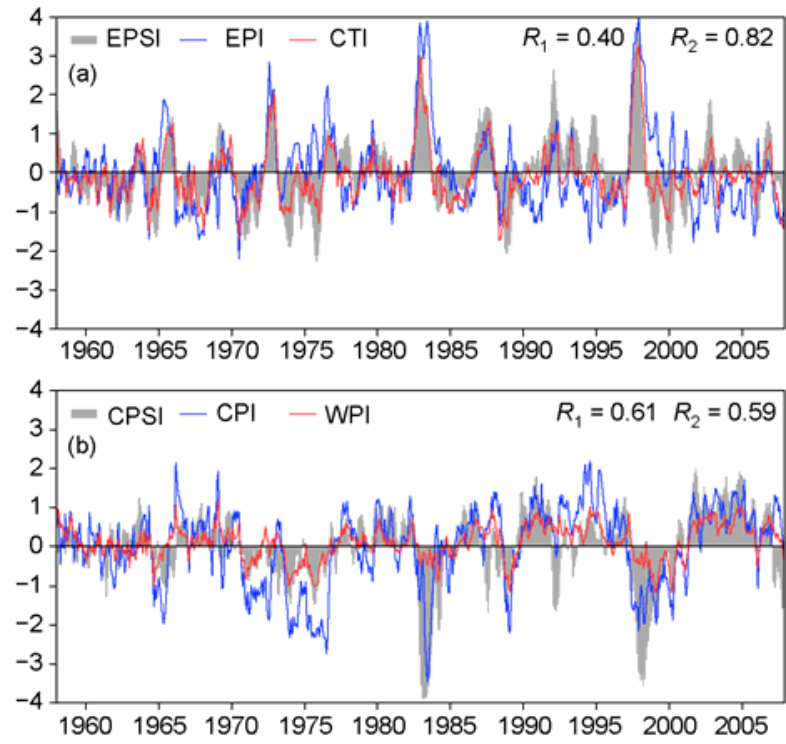

Figure 4 Time series of the normalized (a) eastern Pacific subsurface index (EPSI), EPI defined by Kao and Yu [9] and CTI defined by Ren and Jin [10], (b) central Pacific subsurface index (CPSI), CPI defined by Kao and $\mathrm{Yu}$ [9] and WPI defined by Ren and Jin [10]. $R_{1}$ and $R_{2}$ are the correlation coefficients between EPSI (CPSI) and EPI (CPI), CTI (WPI), respectively.

with the definition by Ren and Jin [10], we found 7 and 10, 15 and 8 cases corresponding to the EP-El Niño and $\mathrm{La} \mathrm{Ni-}$ ña events, CP-El Niño and La Niña events, respectively. Statistical analysis shows that the EPSI can capture all the EP-El Niño events, and seven EP-La Niña cases out of eleven defined by Kao and Yu [9] basically appear in the negative phases of EPSI. Also, the CPSI shows a good capability in distinguishing the CP-ENSO, where $80 \%$ of CP-El Niño events are consistent to the peak phases of CPSI, and all of CP-La Niña events occur in the negative phase of CPSI. In contrast, all the EP-El Niño events and $90 \%$ of EP-La Niña, defined by Ren and Jin [10] are found to be in the peak and the valley phases of the of the EPSI time series, respectively. The percentage of CP-El Niño and La Niña events defined by Ren and Jin [10] occurs in the positive and negative phases of the CPSI are 13/15 and 8/8, respectively.

In addition, we found the frequency and intensity of CP-El Niño events has exhibited an increase trend after the 1980s when the CPSI becomes positive with the larger amplitude. The previous studies emphasized that the SST warming in the central equatorial Pacific is due to those subsurface oceanic processes $[7,8]$ and the subsurface ocean temperature is able to reveal the CP-ENSO [25]. As a result, our result implies that the variation of CPSI on interdecadal time scale possibly indicates the change of the thermocline in the recent decades.

\section{Summary}

The dominant modes of the subsurface ocean temperature (SOT) in the tropical Pacific, and its possible linkage to the
EP and CP-ENSO events during 1958-2007 have been examined. The wavelet analysis suggests the variations of EP and CP-ENSO events bear a close connection to the interannual (2-7 years) and interdecadal (10-15 years) oscillation of the SOT, which is respectively characterized by an dipole mode and a tripole mode in the zonal SOT anomalous field over the tropical Pacific reveled by the SVD analysis. During the mature phase of CP-ENSO, the positive center of SOT on interdecadal time scale at the subsurface layer locates in the west of dateline, and it possibly results in the warming SOT locating in the Niño4 region and causes the CP-SSTA warming.

Based on the EP and CP-ENSO events defined by Kao and $\mathrm{Yu}$ [9] and Ren and Jin [10], we found that the time series of the EP and CP-subsurface indices (EPSI and CPSI) related to the expansion coefficients of the first and the third SVD mode for SOT show a better capability in capturing and disguising the two types of ENSO events. However, due to the impact of EP-ENSO, the long-term trend and the residual signals on the raw SST and SOT anomalies, the third SVD mode in present study could not be fully captured by the simple composite analysis in some of previous works [7,9]. In addition, we noted that corresponding to the increase of the amplitude of the CPSI, the frequency and intensity of CP-El Niño events has exhibited an increase trend after the 1980s, which suggest that the CP-ENSO event has possibly enhanced its impact on the global climate in the past decades.

The authors would like to thank Dr. Tam Chi-Yung and the two anonymous reviewers for their helpful comments and suggestions. This work was supported by the National Natural Science Foundation of China (90711003 and 40921003), the Strategic Priority Research Program of the Chinese Academy of Sciences (XDA05090408), and the Key Program of Chinese Academy of Meteorological Sciences (2010Z003).

1 Rasmusson E M, Carpenter T H. Variation in tropical sea surface temperature and surface wind fields associated with Southern Oscillation/El Niño. Mon Weather Rev, 1982, 110: 354-384

2 Nicholls N. Predictability of interannual variations of Australian seasonal tropical cyclone activity. Mon Weather Rev, 1985, 113: 1144-1149

3 Torrence C, Webster P J. Decadal changes in the ENSO-monsoon system. J Clim, 1998, 12: 2679-2690

4 Power S, Casey T, Folland C, et al. Interdecadal modulation of the impact of ENSO on Australia. Clim Dyn, 1999, 15: 319-324

5 Chang $\mathrm{C}$, Zhang Y, Li T. Interannual and interdecadal variations of the East Asian summer monsoon and tropical Pacific SSTs. Part I: Roles of the subtropical ridge. J Clim, 2000, 13: 4310-4325

6 Larkin N K, Harrison D E. On the definition of El Niño and associated seasonal average U.S. weather anomalies. Geophys Res Lett, 2005, 32: L13705

7 Ashok K, Behera S K, Rao S A, et al. El Niño Modoki and its possible teleconnection. J Geophys Res, 2007, 112: C11007

8 Kug J S, Jin F F, An S I. Two types of El Niño events: Cold tongue El Niño and warm pool El Niño. J Clim, 2009, 22: 1499-1515

9 Kao H Y, Yu J Y. Contrasting Eastern-Pacific and Central-Pacific types of El Niño. J Clim, 2009, 22: 615-632

10 Ren H L, Jin F F. Niño indices for two types of ENSO. Geophys Res Lett, 2011, 38: L04704

11 Weng H Y, Ashok K, Behera S, et al. Impacts of recent El Niño Modoki on dry/wet conditions in the Pacific Rim during boreal summer. 
Clim Dyn, 2007, 29: 113-129

12 Sun F, Yu J Y. A 10-15-year modulation cycle of ENSO intensity. J Clim, 2009, 22: 1718-1735

13 Yu J Y, Kao H K. Decadal changes of ENSO persistence barrier in SST and ocean heat content indices 1958-2001. J Geophys Res, 2007, 112: D13106

14 Yu J Y, Kao H Y, Lee T. Subtropics-related interannual sea surface temperature variability in the equatorial central Pacific. J Clim, 2010, 23: 2869-2884

15 Yu J Y, Kim S T. Three evolution patterns of Central-Pacific El Niño. Geophys Res Lett, 2010, 37: L08706

16 Rayer N A, Parker D E, Horton E B, et al. Global analyses of sea surface temperature, sea ice and night marine air temperature since the late nineteenth century. J Geophys Res, 2003, 108: 4407

17 Carton J A, Chepurin G, Cao X, et al. A simple ocean data assimilation analysis of the global upper ocean 1950-1995. Part 1: Methodology. J Phys Oceanogr, 2000, 30: 294-309

18 Carton J A, Chepurin G, Cao X. A simple ocean data assimilation analysis of the global upper ocean 1950-1995. Part 2: Results. J Phys
Oceanogr, 2000, 30: 311-326

19 Carton J A, Giese B S, Grodsky S A. Sea level rise and the warming of the oceans in the Simple Ocean Data Assimilation (SODA) ocean reanalysis. J Geophys Res, 2005, 110: C09006

20 Giese B S, Ray S. El Niño variability in simple ocean data assimilation (SODA), 1871-2008. J Geophys Res, 2011, 116: C02024

21 Battisti D S, Hirst A C. Interannual variability in the tropical atmosphere-ocean system: Influence of the basic state, ocean geometry, and nonlinearity. J Atmos Sci, 1989, 46: 1687-1712

22 Trenberth K E, Stepaniak D P. Indices of El Niño evolution. J Clim, 2001, 14: 1697-1701

23 Monahan A H. Nonlinear principal component analysis: Tropical Indo-Pacific sea surface temperature and sea level pressure. J Clim, 2001, 14: 219-233

24 Hsieh W W. Nonlinear multivariate and time series analysis by neural network methods. Rev Geophys, 2004, 42: RG1003

25 Yu J Y, Kao H K, Lee T, et al. Subsurface ocean temperature indices for central-Pacific and eastern-Pacific types of El Niño and La Niña events. Theor Appl Climatol, 2011, 103: 337-344

Open Access This article is distributed under the terms of the Creative Commons Attribution License which permits any use, distribution, and reproduction in any medium, provided the original author(s) and source are credited. 